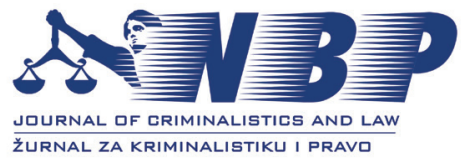

NBP 2021, Vol. 26, Issue 1, pp. 7-19

doi:10.5937/nabepo26-30783

Original scientific paper

\title{
Analysis of the Frequency of Verbal and Vocal Signs in True and False Statements
}

\author{
${ }^{1}$ Valentina Baić, ${ }^{1}$ Zvonimir Ivanović' ${ }^{2}{ }^{2}$ Milan Veljković \\ ${ }^{1}$ University of Criminal Investigation and Police Studies, Belgrade, Serbia \\ ${ }^{2}$ Ministry of Interior of the Republic of Serbia
}

Submitted: 2021-02-08 • Accepted: 2021-05-18 • Published: 2021-05-20

\begin{abstract}
The paper presents research aimed at analysing the frequency of verbal and vocal signs in a situation of false and true statements, by introducing a secondary task. The research involved 100 students ( 47 men and 53 women) of the master's studies of criminal investigation at the University of Criminal Investigation and Police Studies, aged 23-44. Students had the task, based on the observation of twenty selected videos (10 true statements and 10 false statements), to mark the frequency of each individual verbal and vocal sign, on a previously generated and prepared list. The results show that there is a statistically significant difference in terms of the frequency of all verbal and vocal signs in a false or true statement: response latency, speech hesitation, speech errors, speech rate, number of spoken words in the utterance, and length of utterance. Response latency, speech hesitation, and speech errors have higher median values in false utterances than in true ones, while speech rate, number of words spoken, and length of utterance show higher median values in true than false utterances.
\end{abstract}

Keywords: verbal signs, vocal signs, false statement, true statement, cognitive load.
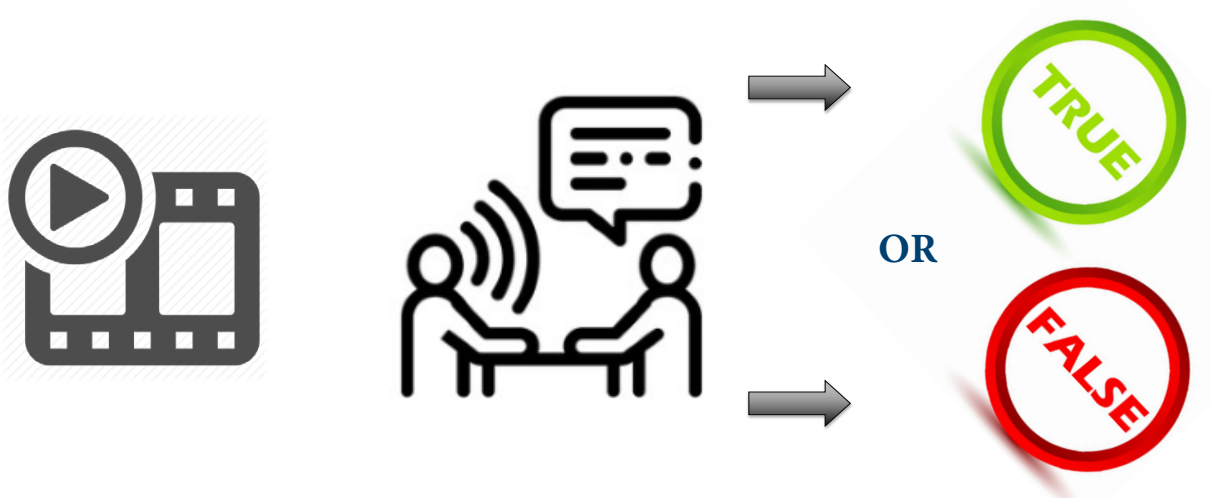

1 Corresponding author: zvonimir.ivanovic@kpu.edu.rs

Citation: Baić, V., Ivanović, Z., \& Veljković, M. (2021). Analysis of the frequency of verbal and vocal signs in true and false statements. NBP. Nauka, bezbednost, policija, 26(1), 7-19. doi:10.5937/nabepo26-30783 


\section{INTRODUCTION}

The interrogation or police questioning process, regardless of whether victims, witnesses or suspects are questioned, is conducted in order to gather information and assess its accuracy. Gathering information is an indispensable segment of any criminal investigation, especially having in mind that the mentioned personal sources have certain information regarding the committed crime (Ivanović \& Baić, 2019). The conversation with the suspect is particularly complex due to the fact that the interrogator (police officer) and the suspect are in the same conflict situation - relation. The suspect seeks to prevent a police officer from establishing his guilt, conceal his involvement or conceal his identity, whereas on the other hand, the police officer strives to resolve the crime, determine all the facts or gather evidence (Ivanović \& Baić, 2019; Milić, 2006). Generally, suspects strive to block the police interrogator's efforts to establish appropriate communication and determine the facts about the subject matter of the examination (Shepherd, 1993). It is a conscious effort of the suspect to deny the truth, fabricate, minimize or augment the facts during the interrogation in order to conceal the truth (Zulawski \& Wicklander, 2002). Those lies are, to some extent, the result of internal anxiety regarding the consequences, and sometimes they could be prepared and elaborate, and sometimes spontaneous and created at the time of questioning. Prepared or planned lies, as opposed to spontaneous lies contain smaller number of signs of deceit or lying (DePaulo et al., 2003). However, a conscious decision to lie, and then withholding the truth and formulating lies, is considered to be a cognitively demanding task (Walczyk et al., 2003; Walczyk et al., 2005), for which reason the presence of signs of lying is expected. Thus, successful lying implies greater cognitive effort. Experts in the field of lie detection explain the phenomenon of cognitive load in several ways. First, they believe that liars should plan what they are going to say, trying not to contradict themselves or the knowledge of the police officer. Second, while answering the stated questions, they need to observe reactions of the interrogators. Finally, they try to control their own behaviour and speech, in order to leave an impression of sincerity (Sporer \& Schwandt, 2006; Vrij et al., 2006; Vrij et al., 2008).

Research shows that in a situation where a suspect gives a false statement, cognitive load leads to more frequent occurrence of some vocal signs, such as: longer pauses in speech (Clark \& Fox Tree, 2002; DePaulo et al., 2003; Vrij \& Mann, 2001), hesitation in speech (Vrij et al., 2001a), longer periods of latency (Vrij et al., 2001b; Vrij et al., 2001c) and more frequent speech errors (Anolli et al., 2003; Vrij \& Mann, 2001). In terms of verbal signs, there is a more frequent presence of some signs, such as: shorter answers to open-ended questions (Colwell et al., 2002), more indirect responses (Burgoon et al., 1996; Zuckerman et al., 1981), less detailed responses (Colwell et al., 2002), etc.

The research conducted in Serbia (Baić \& Batić, 2013) was based on the concept of Vrij, Fisher, Mann and Leal (2008) and included the classical methodology of divided-attention. This concept is based on the assumption that the introduction of a secondary task will be more cognitively demanding in a situation where participants lie than in a situation where they tell the truth, as a result of which different patterns of behaviour will appear in false and true statements. The results of the research 
showed that in the situation of false statement the participants gave shorter answers to the questions asked and had longer periods of latency, which means that they took longer breaks before answering the questions asked. In addition, the participants had a lower achievement in the secondary task, more precisely, the computer game of ski simulation. The research confirmed the assumption that the introduction of a secondary task was cognitively more demanding in the situation of false statement than in the situation of true statement.

Since the results of previous research (Baić \& Batić, 2013) showed the justification of further research, the basic problem of this research can be expressed by the following question: What is the frequency of verbal and vocal signs in a situation of false and true statement, by applying the described methodology and introducing a secondary task? Based on the results of previous research, it can be expected that the secondary task will limit the cognitive resources of the participants, due to which significant differences in the frequency of verbal and vocal signs will appear in false and true statements.

\section{Sample}

The research involved 100 students (47 men and 53 women) of master studies of criminal investigation at the University of Criminal Investigation and Police Studies, aged 23-44, average age 27, who voluntarily filled in the questionnaire during school hours. In the preparatory phase with the aim of avoiding implicit assumptions of deceitfulness, the students are presented the knowledge about verbal and vocal signs that are characteristic for the lying situations. The students were divided into ten groups. Each group had ten students. Each student performed the assessment independently, and then each group gave a unique assessment in terms of the frequency of each verbal or vocal sign. All students signed an informed consent to participate in the research, including the participants who evaluated as well as those who participated in the recording of the video material.

\section{Stimuli}

The set of stimuli consisted of twenty videos (10 true statements and 10 false statements), selected on the basis of previous research (Baić \& Batić, 2013). In the mentioned research, a total of 30 interviews were recorded (15 false statements and 15 true statements), of which 20 interviews were selected at random. Specifically, every third recording was not included in the research. Applying the paradigm of divided attention, which implies performing two tasks at the same time, the participants simultaneously described the appearance of the bag and the object and played a computer simulation of skiing. In a false statement situation, participants had the task to describe the appearance of the bag and the objects they had allegedly taken from the bag, while in the situation of the true statement, they had the task to describe the appearance of the object and the bag from which they actually had taken the object. All participants described objects of different shapes, colours, sizes and purposes. During the interview, when describing the bag and the object, the participants had a secondary task which included playing a computer game (ski simulation) intended

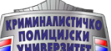


for one player, who has the task to control skiers on a mountain slope, avoiding obstacles while racing against time (ORF-Ski Challenge version: 2007).

\section{Procedures}

The research was conducted in the premises of the University of Criminal Investigation and Police Studies, where the students had the task to view twenty videos, i.e. interviews with persons who gave false and true testimonies, mark the frequency of each individual verbal and vocal sign. The videos of the interviewees were displayed through a video projector, in random order, and the students recorded the presence of verbal and vocal signs on the previously prepared list after each shown video.

\section{Design}

For the purpose of this research, a list of verbal and vocal signs with descriptions was made. The list included the following vocal signs: response latency, speech hesitation, speech errors, speech rate, and the following verbal signs: utterance length and number of words spoken. The students recorded the frequency of each verbal and vocal sign on the mentioned list, i.e. the number of their appearances or the number of manifestations. Definitions of the dependent variables:

1) Latency period: period of silence between a question and an answer;

2) Speech hesitations: use of speech fillers, e.g., "ah", "um", "er", "uh" and "hmmm";

3) Speech errors: grammatical errors, word and/or sentence repetition, false starts, sentence change, sentence incompletions, slips of the tongue, etc.;

4) Speech rate: number of spoken words in a certain period of time;

5) Response length: how long the participant's answer lasts, without questioning interviewers, expressed in seconds;

6) Number of words spoken: the total number of words spoken in the statement.

The independent variable was coding whether the individual in the video recording was telling the truth or not.

\section{Statistical analyses}

IBM SPSS version 20.0 software package was used for data entry and processing. Within the descriptive statistics, the data are presented by measures of central tendency (arithmetic mean, median) and measures of variability (range, standard deviation, interquartile range). Numerical characteristics of observations were processed within descriptive statistics and with the help of frequencies, in order to show the representation of a certain category or answer. Within the method of comparative statistics, the following analyses were applied: Wilcoxon test of equivalent pairs (non-parametric technique of examining differences for dependent measures) in order to determine the existence of a statistically significant difference in frequency/production of certain verbal and vocal signs between true and false statements. Cluster analysis (analysis with the help of a graphical representation of the so-called dendrogram) was also applied in order to perform the categorization of signs independently in true and false statements. In order to check the degree of agreement 
between the assessors (group of assessors) in determining the defined signs, interclass correlation coefficients (ICC) were calculated. In the applied tests, the threshold values of risk probability are at the level of significance of $95 \%(\mathrm{p}<0.05)$ (difference of statistical parameters significant) and 99\% ( $\mathrm{p}<0.01)$ (difference of statistical parameters highly significant).

\section{RESULTS}

In order to determine the relative homogeneity of groups of different signs in true and false statements, descriptive statistics was applied. The analysis of the frequency of objective signs in true and false statements is shown in Table 1, and is presented using descriptive indicators, measures of central tendency and scattering. As it can be seen in the table (based on the median and arithmetic means determined for the frequency of all signs in a false and true statement), it can be envisioned that for the variables response latency, speech hesitation and speech errors, the arithmetic mean and median are higher in the case a false statement in relation to a true statement, while for the variables of the speed of speech, the number of spoken words and the length of the statement, the arithmetic mean and the median are higher in the case of a true statement in relation to a false statement.

Table 1. Descriptive indicators of the frequency of objective signs in true and false statements $(N=20)$

\begin{tabular}{|c|c|c|c|c|c|c|c|}
\hline Sample description & $\min$ & $\max$ & $\begin{array}{l}\text { Arith. } \\
\text { mean }\end{array}$ & Median & $\begin{array}{c}\text { Stand. } \\
\text { deviation }\end{array}$ & $\begin{array}{c}1 . \\
\text { quartiles }\end{array}$ & $\begin{array}{c}3 . \\
\text { quartiles }\end{array}$ \\
\hline Latency period - false statement & 2 & 8 & 4.90 & 5 & 1.62 & 4 & 6 \\
\hline Latency period - true statement & 0 & 4 & 1.00 & 1 & 1.21 & 0 & 1 \\
\hline Speech hesitations - false statement & 3 & 30 & 11.90 & 8.5 & 8.23 & 5 & 17.50 \\
\hline Speech hesitations - true statement & 0 & 18 & 4.45 & 3.5 & 4.22 & 1.25 & 6 \\
\hline Speech errors - false statement & 1 & 20 & 4.85 & 3 & 4.25 & 3 & 6.75 \\
\hline Speech errors - true statement & 0 & 6 & 1.35 & 1 & 1.42 & 0.25 & 2 \\
\hline Speech rate - false statement & .94 & 1.71 & 1.26 & 1.2 & 0.23 & 1.11 & 1.49 \\
\hline Speech rate - true statement & 1.30 & 2.37 & 1.73 & 1.7 & 0.28 & 1.53 & 1.93 \\
\hline $\begin{array}{l}\text { Number of words spoken - false } \\
\text { statement }\end{array}$ & 28 & 100 & 58.00 & 60 & 19.40 & 43.25 & 69.50 \\
\hline $\begin{array}{l}\text { Number of words spoken - true } \\
\text { statement }\end{array}$ & 70 & 138 & 106.25 & 106 & 20.23 & 92.75 & 126.25 \\
\hline Response length - false statement & 28 & 69 & 44.95 & 44.5 & 9.97 & 37.75 & 51.75 \\
\hline Response length - true statement & 38 & 81 & 62.15 & 62 & 12.31 & 55 & 71 \\
\hline
\end{tabular}


In order to categorize objective signs in a false statement, cluster analysis (analysis with the help of a graphical representation of the so-called dendrogram) was applied. The obtained results show that, based on the method of complete connection applied on squared Euclidean distances between variables, a solution on the formation of two clusters is acceptable in a false statement. The first cluster is formed by the following signs in a false statement: response latency, speech speed, speech errors and hesitation in speech, while the second cluster is formed by the number of spoken words and the length of the statement.

\section{Latency period - false statement \\ Speech rate - false statement \\ Speech errors - false statement \\ Speech hesitations - false statement \\ Number of words spoken - false statement \\ Response length - false statement}

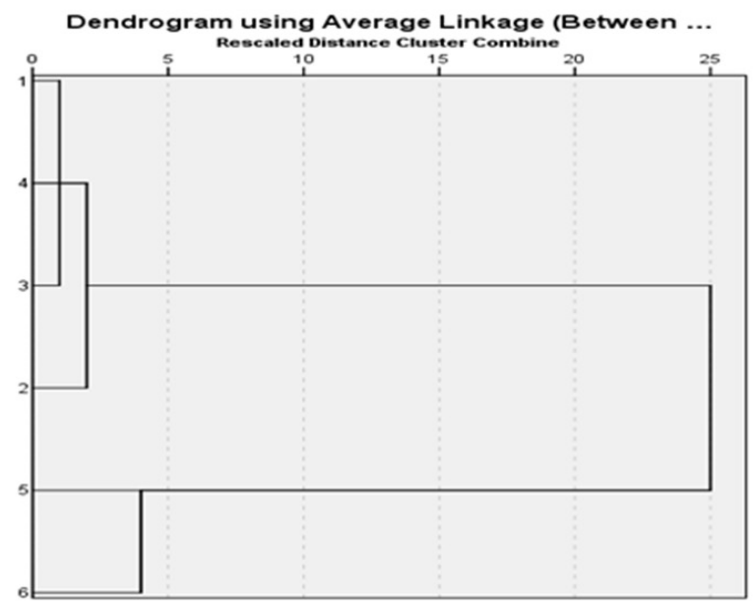

Figure 1. Dendogram showing the results of cluster analysis in false statements

In other words, the cluster analysis showed that the students recognized two groups of signs in a false statement, which indicates that the mentioned signs are more often noticed together.

Table 2. Review of cluster affiliation in false statements

\begin{tabular}{lc}
\hline Indicator & Cluster affiliation \\
\hline Latency period - false statement & 1 \\
Speech hesitations - false statement & 1 \\
Speech errors - false statement & 1 \\
Speech rate - false statement & 1 \\
Number of words spoken - false statement & 2 \\
Response length - false statement & 2 \\
\hline
\end{tabular}


In order to categorize the signs in the true statement, cluster analysis was also applied. The obtained results show that based on the method of complete connectivity applied at squared Euclidean distances between variables, a solution on the formation of two clusters is acceptable. The first cluster is formed by the following signs in a true statement: response latency, speech speed, speech errors and hesitation in speech, while the second cluster is formed by the number of spoken words and the length of the statement. As with the previously conducted cluster analysis in the case of a false statement, this analysis also showed that the students recognized two groups of signs in a true statement, which indicates that these signs are more often observed together.

\section{Latency period - true statement \\ Speech rate - true statement \\ Speech errors - true statement \\ Speech hesitations - true statement \\ Number of words spoken - true statement \\ Response length - true statement}

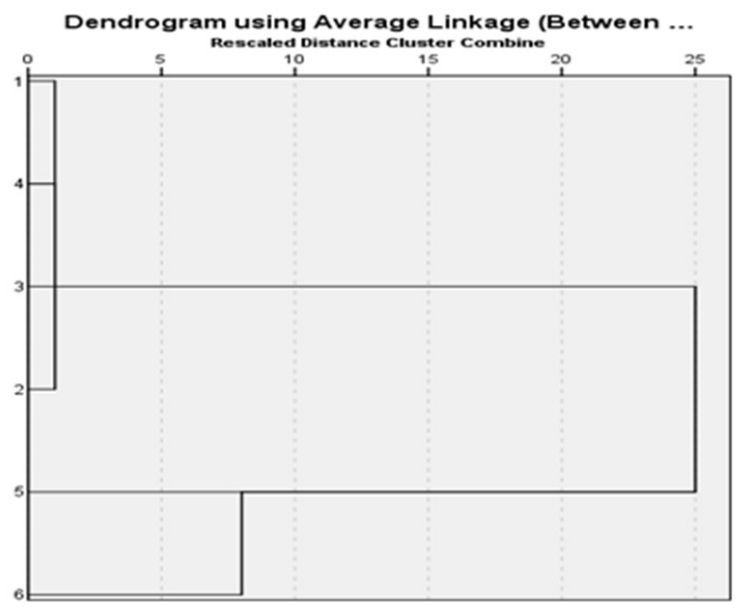

Figure 2. Dendogram showing the results of cluster analysis in true statements

Table 3. Display of cluster affiliation in true statements

\begin{tabular}{lc}
\hline Indicator & Cluster affiliation \\
\hline Latency period - true statement & 1 \\
Speech hesitations - true statement & 1 \\
Speech errors - true statement & 1 \\
Speech rate - true statement & 1 \\
Number of words spoken - true statement & 2 \\
Response length - true statement & 2 \\
\hline
\end{tabular}

In order to determine whether there are statistically significant differences in the frequency of individual signs, in the situations of false and true testimonies, a non-parametric technique of testing differences for dependent measures was applied - Wilcoxon test of equivalent pairs. The following tables show Wilcoxon test values and significance levels, as well as arithmetic means and medians for each indicator. 
Table 4. Differences in the average frequency of signs in false and true statements

\begin{tabular}{lccccc}
\hline Variable & The group & $\begin{array}{c}\text { Arith. } \\
\text { mean }\end{array}$ & Median & $\mathbf{Z}$ & $\boldsymbol{p}$ \\
\hline \multirow{2}{*}{ Latency period } & false statement & 4.90 & 5.0 & -3.931 & .000 \\
& true statement & 1.00 & 1.0 & & \\
Speech hesitations & false statement & 11.90 & 8.5 & -3.927 & .000 \\
& true statement & 4.45 & 3.5 & & \\
Speech errors & false statement & 4.85 & 3.0 & -3.944 & .000 \\
\multirow{3}{*}{ Speech rate } & true statement & 1.35 & 1.0 & & \\
\multirow{2}{*}{ Number of words spoken } & false statement & 1.26 & 1.2 & -3.921 & .000 \\
& true statement & 1.73 & 1.7 & & \\
Response length & false statement & 58.0 & 60.0 & -3.921 & .000 \\
& true statement & 106.25 & 106.0 & & \\
& false statement & 44.95 & 44.5 & 3.923 & .000 \\
\hline
\end{tabular}

The results obtained using the Wilcoxon test of equivalent pairs indicate that for all signs there is a statistically significant difference in terms of frequency between false and true statements: response latency $(Z=-3.931, p=0.000)$, speech hesitation $(Z$ $=-3.927, p=0.000)$, speech errors $(Z=-3.944, p=0.000)$, speech rate $(Z=-3.921$, $\mathrm{p}=0.000)$, number of spoken words in the statement $(\mathrm{Z}=-3.921, \mathrm{p}=0.000)$ and length of statement $(Z=-3.923, p=0.000)$. As shown in Table 4 , by reviewing the median, it can be seen that response latency, hesitation in speech, and speech errors have higher median values in the false than in the true statements. On the other hand, when it comes to the speed of speech, the number of spoken words and the length of the statement, there are higher values of the median in the true than in the false statements.

In order to check the degree of agreement between the evaluators, the interclass correlation coefficient was calculated, more precisely, the model of two-way random effect was applied with the excluded influence of the students from the denominator. Based on a $95 \%$ confidence interval, ICC values below 0.50 can be treated as low agreement, between 0.50 and 0.75 as moderate, between 0.75 and 0.90 as good and above 0.90 as excellent stacking (Koo \& Li, 2016).

Table 5. Interclass correlation coefficient in false statements

\begin{tabular}{lccccc}
\hline Measurement & $\begin{array}{c}\text { Interclass correlation } \\
\text { (ICC) }\end{array}$ & Lower limit & Higher limit & F & p \\
\hline Individual measurement & .888 & .743 & .980 & 159.13 & .000 \\
Average measurement & .994 & .983 & .999 & 159.13 & .000 \\
\hline
\end{tabular}


The obtained results show that the interclass correlation coefficient (ICC) for all characters in the false statement is: ICC $=0.994$ and moves in the interval; $95 \% \mathrm{CI}$, 0.983-0.999, which indicates an excellent agreement among students (groups) on the frequency of their occurrence.

Table 6. Interclass correlation coefficient in true statements

\begin{tabular}{lccccc}
\hline Measurement & $\begin{array}{c}\text { Interclass correlation } \\
\text { (ICC) }\end{array}$ & Lower limit & Higher limit & F & p \\
\hline Individual measurement & .961 & .900 & .993 & 491.14 & .000 \\
Average measurement & .998 & .994 & 1.00 & 491.14 & .000 \\
\hline
\end{tabular}

The obtained results show that the interclass correlation coefficient (ICC) for all signs in a true statement is: ICC $=0.998$ and moves in the interval; 95\% CI, 0.9941.00 , which also indicates an excellent agreement among the students on the frequency of occurrence of signs in a true statement.

\section{DISCUSSION}

Experts in the area of deception detection have long argued that deception is accompanied by an increase in cognitive load. Although this argument lacked a solid theoretical basis, there are still some logical assumptions that support this claim, which we mentioned in the introductory part (Buller \& Burgoon, 1996; Granhag \& Vrij, 2005; Vrij \& Mann, 2001; Sporer \& Schwandt, 2007; Zuckerman et al., 1981). The results of this research support the claim that lying requires more mental resources than telling the truth, and that individuals are aware of the increased cognitive demands that accompany the process of lying.

When studying cognitive processing using a cognitive capacity model, researchers have traditionally observed performing a secondary task (Baić \& Batić, 2013; Eysenck \& Eysenck, 1979; Johnston \& Heinz, 1979; Logan, 1979). This research builds on previous studies that applied a divided attention methodology to limit the cognitive resources of research participants, by introducing a secondary task (Baić \& Batić, 2013; DePaulo et al., 2003; Vrij et al., 2008; Walczyk et al., 2005). We expected that the secondary task would limit the cognitive resources of the participants, due to which significant differences in the frequency of verbal and vocal signs would appear in the false and true statement. More precisely, we expected that the signs of cognitive load would be more manifested in a false statement.

In the research of Baić and Batić (2013) using the described methodology, the participants who gave a false statement compared to the participants who told the truth, had poorer achievement on the secondary task, gave shorter answers to the questions and had longer latency period. The results show that the variables of response latency, speech hesitation and speech errors are more often present in the situation of a false statement, while the variables of speech rate, number of spoken words and the length of the statement are more often present in the situation of a true statement. The results of this research indicate that latency of response and hesitation in 
speech, which basically require certain pauses in speech, appear more frequently in false than true statements. Thus the assumption that speech errors and pause rates are higher in false than true testimony was supported. At the same time, this can imply that there is a certain connection between deception and pauses in speech, i.e. that deception is more correlated with cognition, which leads to longer latencies in speech, hesitation in speech and, inevitably, to errors in speech.

The results regarding true statements show that these statements differ significantly from false statements in terms of the length of the answer, the number of words spoken and the speed of speech. True statements basically lasted longer. A greater number of words were uttered in less time than in the case of false statements. At the same time, there were fewer periods of latency, less hesitation in speech and fewer speech errors in these statements. The conclusions we have reached suggest that truth-tellers utter more words and have longer utterances, which is in line with Undeutsch's hypothesis (Undeutsch, 1984), according to which a statement based on a true event will differ in content, structure and quality of detail compared to a statement that is false.

\section{LIMITATIONS}

A potential limitation of the research is an insufficiently examined ecological validity of the results obtained on student samples, in relation to the real suspects, since the research was conducted in experimental conditions in which the participants did not lie spontaneously. Assessing honesty in the laboratory is very difficult for at least two reasons. First, there are individual differences between participants who lie and those who tell the truth, and the motivation of liars to avoid being exposed. The second limitation concerns the relatively small number of videos (10 true statements and 10 false statements), on the basis of which the participants recorded the frequencies of each individual verbal and vocal sign. These limitations could be partially overcome by increasing the number of videos and applying a new research paradigm, in order to increase the motivation of participants to lie better, such as payment of compensation for participation in the research, obtaining a larger number of pre-examination points, etc. Finally, the draft study did not include a control group, which would contribute to more relevant conclusions.

\section{CONCLUSIONS}

If we keep in mind the limitations that accompanied this research, we assume that what the students noticed while watching the video, i.e. interviews with participants who lied and told the truth, related to another variable, which referred whether participants were telling the truth. Bearing in mind that the participants were engaged in a computer game of ski simulation (which was a secondary task) while answering the questions, we can conclude that the cognitive load was more harmful to individuals who lied. 
Participants who lied hesitated before answering questions, taking longer pauses and speaking errors to construct sentences. Clusters of these verbal and vocal signs indicate an increased likelihood of lying, although all signs of deception are more relevant when compared to nonverbal signs as well. Since the control group was not included in the research, we can only assume that the cognitive load was what created the difference in the behaviour of the participants who told the truth and lied. This implies that if we want to test the influence of cognitive load on the appearance of a difference in the behaviour of person who lie and those who tell the truth, we should definitely introduce a control group.

Future research would be desirable to focus on interrogation techniques that reduce the mental resources of suspects. The goal would be to devise new interrogation techniques that would increase the difference between suspects who lie and those who tell the truth.

\section{ACKNOWLEDGMENTS}

The authors would like to express their gratitude to the reviewers for the comments that greatly improved this manuscript.

\section{REFERENCES}

Anolli, L., Balconi, M., \& Ciceri, R. (2003). Linguistic styles in deceptive communication: Dubitative ambiguity and elliptic eluding in packaged lies. Social Behavior and Personality, 31(7), 687-710. https://doi.org/10.2224/sbp.2003.31.7.687

Baić, V., \& Batić, S. (2013). Značaj koncepta povećanog kognitivnog opterećenja u detekciji laganja. In A. Kostić (Ed.), Zbornik radova sa XIX naučnog skupa Empirijska istraživanja u psihologiji (pp. 19-24). Filozofski fakultet Univerziteta u Beogradu.

Buller, D. B., \& Burgoon, J. K. (1996). Interpersonal deception theory. Communication Theory, 6(3), 203-242. https://doi.org/10.1111/j.1468-2885.1996.tb00127.x

Burgoon, J. K., Buller, D. B., Floyd, K., \& Grandpre, J. (1996). Deceptive realities: Sender, receiver, and observer perspectives in deceptive conversations. Communication Research, 23(6), 724-748. https://doi.org/10.1177\%2F009365096023006005

Clark, H. H., \& Fox Tree, J. E. (2002). Using uh and um in spontaneous speaking. Cognition, 84(1), 73-111. https://doi.org/10.1016/s0010-0277(02)00017-3

Colwell, K., Hiscock, C. K., \& Memon, A. (2002). Interview techniques and the assessment of statement credibility. Applied Cognitive Psychology, 16(3), 287-300. https://doi.org/10.1002/acp.788

DePaulo, B. M., Lindsay, J. J., Malone, B. E., Muhlenbruck, L., Charlton, K., \& Cooper, H. (2003). Cues to deception. Psychological Bulletin, 129(1), 74-118. https://doi. org/10.1037/0033-2909.129.1.74 
Eysenck, M. W., \& Eysenck, M. C. (1979). Processing depth, elaboration of encoding, memory store and expended processing capacity. Journal of Experimental Psychology: Human Learning and Memory, 5(5), 472-484. https://psycnet.apa.org/ doi/10.1037/0278-7393.5.5.472

Granhag, P. A., \& Vrij, A. (2005). Deception detection. In N. Brewer \& K. Williams (Eds.), Psychology and law: An empirical perspective (pp. 43-92). Guilford Press.

Ivanović, Z., \& Baić, V. (2019). Taktika obezbeđivanja iskaza. Kriminalističko-policijski univerzitet.

Johnston, W. A., \& Heinz, S. P. (1979). Depth of nontarget processing in an attention task. Journal of Experimental Psychology, 5(1), 168-175. https://doi. org/10.1037//0096-1523.5.1.168

Koo, T. K., \& Li, M. Y. (2016). A guideline of selecting and reporting intraclass correlation coefficients for reliability research. Journal of Chiropractic Medicine, 15(2), 155-163. https://dx.doi.org/10.1016\%2Fj.jcm.2016.02.012

Logan, G. D. (1979). On the use of a concurrent memory load to measure attention and automaticity. Journal of Experimental Psychology: Human Perception and Performance, 5(2), 189-207. https://psycnet.apa.org/doi/10.1037/0096-1523.5.2.189

Milić, N. (2006). Policijsko saslušavanje osumnjičenog. Policijska akademija.

Shepherd, E. (1993). Aspects of police interviewing. British Psychological Society.

Sporer, S. L., \& Schwandt, B. (2006). Paraverbal indicators of deception: A meta-analytic synthesis. Applied Cognitive Psychology, 20(4), 421-446. https://psycnet.apa. org/doi/10.1002/acp.1190

Sporer, S. L., \& Schwandt, B. (2007). Moderators of nonverbal indicators of deception. Psychology, Public Policy, and Law, 13(1), 1-34. https://psycnet.apa.org/ doi/10.1037/1076-8971.13.1.1

Undeutsch, U. (1984). Courtroom evaluation of eyewitness testimony. International Review of Applied psychology, 33(1), 51-67. https://psycnet.apa.org/ doi/10.1111/j.1464-0597.1984.tb01416.x

Vrij, A., Edward, K., \& Bull, R. (2001a). Stereotypical verbal and nonverbal responses while deceiving others. Personality and Social Psychology Bulletin, 27(7), 899-909. https://doi.org/10.1177\%2F0146167201277012

Vrij, A., Edward, K., \& Bull, R. (2001b). People's insight into their own behaviour and speech content while lying. British Journal of Psychology, 92(2), 373-389. https://doi. org/10.1348/000712601162248

Vrij, A., Edward, K., \& Bull, R. (2001c). Police officers' ability to detect deceit: The benefit of indirect deception detection measures. Legal and Criminological Psychology, 6(2), 185-196. https://psycnet.apa.org/doi/10.1348/135532501168271

Vrij, A., Fisher, R., Mann, S., \& Leal, S. (2006). Detecting deception by manipulating cognitive load. Trends in Cognitive Sciences, 10(4), 141-142. https://doi. org/10.1016/j.tics.2006.02.003 
Vrij, A., Fisher, R., Mann, S., \& Leal, S. (2008). A cognitive load approach to lie detection. Journal of Investigative Psychology and Offender Profiling, 5(1-2), 39-43. http://dx.doi.org/10.1002/jip.82

Vrij, A., \& Mann, S. (2001). Telling and detecting lies in a high-stake situation: The case of a convicted murderer. Applied Cognitive Psychology, 15(2), 187-203. https://psycnet.apa.org/doi/10.1002/1099-0720(200103/04)15:2\%3C187::AIDACP696\%3E3.0.CO;2-A

Walczyk, J. J., Roper, K. S., Seemann, E., \& Humphrey, A. M. (2003). Cognitive mechanisms underlying lying to questions: Response time as a cue to deception. Applied Cognitive Psychology, 17(7), 755-774. https://doi.org/10.1002/acp.914

Walczyk, J. J., Schwartz, J. P., Clifton, R., Adams, B., Wei, M., \& Zha, P. (2005). Lying person-to-person about live events: A cognitive framework for lie detection. Personnel Psychology, 58(1), 141-170. https://doi.org/10.1111/j.1744-6570.2005.00484.x

Zuckerman, M., DePaulo, B.M., \& Rosenthal, R. (1981). Verbal and nonverbal communication of deception. Advances in experimental social psychology, 14, 1-59.

Zulawski, D. E., \& Wicklander, D. E. (2001). Practical aspects of interview and interrogation (2nd ed.). CRC Press. 
